NASA Technical Memorandum 105659

\title{
Development of Advanced Seals for Space Propulsion Turbomachinery
}

R.C. Hendricks and A.D. Liang

Lewis Research Center

Cleveland, Ohio

D.W. Childs

Texas A\&M University

College Station, Texas

and

M.P. Proctor

Lewis Research Center

Cleveland, Ohio

Prepared for the

1992 Aerospace Atlantic International Conference and Exposition sponsored by the Society of Automotive Engineers

Dayton, Ohio, April 6-10, 1992 


\title{
DEVELOPMENT OF ADVANCED SEALS FOR SPACE PROPULSION TURBOMACHINERY
}

\author{
R.C. Hendricks and A.D. Liang \\ National Aeronautics and Space Administration \\ Lewis Reseach Center \\ Cleveland, Ohio 44135 \\ D.W. Childs \\ Texas A\&M University \\ College Station, Texas \\ M.P. Proctor \\ National Aeronautics and Space Administration \\ Lewis Reseach Center \\ Cleveland, Ohio 44135
}

\section{ABSTRACT}

Current activities in seals for space propulsion turbomachinery that the NASA Lewis Research Center sponsors are surveyed. The overall objective is to provide the designer and the researcher with the concepts and the data to control seal dynamics and leakage. Included in the program are low-leakage seals, such as the brush seal, the "ceramic rope" seal, low-leakage seals for liquid oxygen turbopumps, face seals for two-phase flow, and swirl brakes for stability. Two major efforts are summarized: a study of seal dynamics in rotating machinery and an effort in seals code development.

\section{INTRODUCTION}

Early rocket engine turbomachines were equipped with either labyrinth seals, face seals, or a combination of the two to control leakage. As the operational requirements of machines increase, the seal performance goals of low leakage, long life, and low power loss have become more stringent. The current seal designs may be inadequate in terms of supporting dynamic excursions and controlling leakage. The NASA Lewis Research Center has therefore been involved in developing new designs as well as in modifying existing designs in response to the seal requirements of space propulsion turbomachinery.
This paper provides an overview of seal technology efforts under the Earth-to-Orbit Propulsion and the Space Chemical Engine Technology programs. Included are studies of seal dynamics, development of seal codes, and experimental evaluation of advanced concepts. Advanced seal designs, such as the brush seal, the ceramic rope seal, advanced lowleakage seals for liquid oxygen turbopumps, and face seals for twophase flow, are the current interests of the program. The seals developed in these studies are applicable to aircraft engines and low- and high-thrust rocket engines. There is a vast source of information in the literature on seals and dynamics. This paper only cites selective references in support of the discussions provided in the text. A limited review of the NASA seals program has been presented to the industry. ${ }^{1}$ It described some sealing concepts including labyrinth seals, abradable seals (felt metal and honeycomb), high-compliance seals (brush and ceramic rope), and smart seals.

\section{BACKGROUND}

In normal operations the noncontacting labyrinth seal provides excellent leakage control with low power consumption, but dynamic excursions can inflict severe damage on the shaft or shroud and on the seal itself. Several 
seal design concepts are being investigated to address dynamic excursions in the shaft.

Contacting seals have the lowest leakage but the highest wear rate. Fixed-clearance seals have the longest life but the highest leakage rates. With appropriate geometry, such as spiral grooves or Raleigh steps, hydrodynamic seals can follow shaft dynamics. Face seals can be designed to provide low leakage and positive closure at zero surface speed. ${ }^{2-9}$

Two-phase flow in seals occurs in nearly all cryogenic turbomachines at some time during their operation. This can lead to rotordynamic instabilities. However, if properly controlled, face seals can promise even greater stability and leakage control in two-phase flows than in gaseous or liquid working fluids ${ }^{16}$. Today's turbomachines have geometry control devices, swirl brakes, coning, or damper seals that increase their stability margins. But less than a decade ago seal-driven rotordynamic instabilities and their detrimental effects on performance were not fully understood. The realization that seals contribute significantly to turbomachinery rotordynamic stability was largely due to a strong effort on rotordynamic instabilities initiated by the NASA Lewis Research Center.

Currently, the contacting brush seal and its derivatives are proposed for meeting flexible turbomachine requirements $\mathbf{s}^{\mathbf{9 1 4 - 2 4}}$ but little is available in the literature detailing their life in harsh turbomachine environments. Brush seals and their potential applications are being studied by researchers at NASA Lewis.1,26-24

Computational fluid dynamics (CFD), computer-aided design (CAD), knowledge-based systems (KBS), benchmark experiments, and flow modeling are providing redesigns of seals with and without special grooving that can withstand the rigors of aerospace turbomachines while still providing reduced leakage and increased stability.
Concurrently, the smart seal concept, microelectronics, and feedback control circuitry are being introduced to provide even better sealing concepts.

\section{BRUSH SEALS}

Brush seal systems are being proposed to replace labyrinth seals because they are compliant and reliable, offer less leakage at lower cost, and can enhance rotor stability. A typical brush seal is illustrated in Figure 1 . Experimental studies are being conducted to investigate hightemperature and cryogenic applications of brush seals.

Brush seal for high-temperature applications - Brush seals are being evaluated for applications in the turbine end of the hydrogen or oxygen turbopump, as well as in the T-700 helicopter engine turbine. The latter is an effort sponsored by the Army Propulsion Directorate at the NASA Lewis Research Center and complements the seals program for rocket engine turbomachinery.

NASA Lewis Research Center has acquired a hot-gas brush seals tester from the U.S. Air Force. The basic apparatus, illustrated in Figure 2, was designed for operation to $200 \mathrm{psi}$ at $1500^{\circ} \mathrm{F}$ and $40,000 \mathrm{rpm}$ $(890 \mathrm{ft} / \mathrm{sec}$ for a $5.1-i \mathrm{in}$-borediameter seal) with air.16,17 The installation at NASA will provide operations up to $150 \mathrm{psi}$ and $600^{\circ} \mathrm{F}$ at rotational speeds to 30,000 or to $40,000 \mathrm{rpm}$ with rotor modifications. Leakage can be measured at different pressure drops across the seal.

To control the pressure drop across the brush, the upstream pressure is fixed and the back pressure is manipulated. For gaseous flows this method produces a conventional aperture-choke pressure profile. Brush seals of 5.1-in. bore diameter (Fig. 1) provided by several seals manufacturers have previously been tested in this manner under an Air Force contract and serve as a data base.16-18

As currently designed, the tester cannot assess rotordynamics. 
Techniques to offset the rotor or the housing in order to determine the effects of eccentricity on leakage and wear are under investigation. Some effects of eccentricity on leakage were determined in a bench-scale test rig.

Brush seals are also being tested in a small turbine engine, the T-700. The objective is to improve engine performance by reducing the parasitic airflow from the compressor through the outer gas path seal. The existing outer gas path seal of the fourth-stage T-700 turbine is a honeycomb labyrinth configuration. Brush seals have been instrumental in reducing leakages over equivalent labyrinth seals and do not degrade rotor stability. In addition, because the brush seals are compliant, they can accommodate surface deformation and dynamic perturbations without damage whereas labyrinths cannot.

\section{Brush seal for cryogenic} applications - Information on brush seals has primarily been obtained from gas compressors and turbines. To establish the baseline data for liquid oxygen and liquid hydrogen turbopump applications, the brush seal system needs to be evaluated in cryogenic conditions.

The basic apparatus for testing the cryogenic brush seal is shown in Figure 3. It has been designed for conventional or brush seal testing with up to five brushes in series. Currently being constructed at Lewis, the system will be capable of rotational speeds to $40,000 \mathrm{rpm}$ ( 350 $\mathrm{ft} / \mathrm{sec}$ for a 2.0-in.-diameter rub runner) and to $60,000 \mathrm{rpm}$ with a shorter rub runner (525 ft/sec for a 2.0-in.-diameter rub runner).

The system can be operated by controlling either the back pressure or the inlet pressure. Most testing will be conducted with liquid nitrogen as the working fluid. The use of corresponding states will provide brush seal results for liquid oxygen over a wide range of conditions. $21,22,25-29$

\section{CERAMIC ROPE SEALS}

In some hypersonic engine configurations, linear brush, wafer, or rope seals are proposed to seal engine sidewalls that can be distorted up to 0.15 in. ${ }^{36}$, yet maintain leakages of less than 0.004 $1 \mathrm{~b}$-sec/ft of seal.

The ceramic wafer seal consists of a stack (or stacks) of planar elements, such as smooth-surface, high-density ceramic wafers, and a backing plate that is deformed by a series of actively cooled bellows to force the wafers to conform to the passage geometry. This configuration can withstand pressure differences to over 100 psi and temperatures to 2300 to $2500^{\circ} \mathrm{F}$ when it is aided by transpiration cooling.

The braided ceramic rope seal can be fabricated in a variety of configurations, as illustrated in Figure 4, typically in either twoor three-dimensional weaves. The ceramic fibers are fabricated more like a cable with twisted internal strands for structural loading and support for the flexible outer wrapping. The fibers have a lower thermal and mechanical limit than the ceramic stacks, but their conformability, ease of fabrication, and low leakage make them attractive.

For these low-leakage configurations a channel flow model for the ceramic wafers and a flow resistance model for the woven configurations were found to be very effective in predicting leakage. These seals are of great interest to the NASA Lewis research program and are being investigated along with the brush seal effort.

\section{LOW-LEAKAGE SEALS FOR LIQUID OXYGEN TURBOPUMPS}

Helium-buffered, floating-ring seals are presently employed on the Space Shuttle Main Engine (SSME) oxidizer turbopumps to prevent mixing of the oxidizer and turbine gases. Average consumption of gaseous helium per pump is 250 to 
300 scfm. This load has to be carried by the vehicle and therefore has a strong effect on engine performance and payload.

A study is currently under way to obtain improved-performance purge seals for the SSME oxidizer pump. ${ }^{31}$ Computer codes have been developed for analyzing a variety of gaslubricated, floating-ring and sector seals, for analyzing and optimizing gas-lubricated, spiral-groove face seals, and for determining face seal response to runner excitations in as many as five degrees of freedom. These codes were used to analyze hydrostatic ring, segmented ring, and face seals; axial-stepped, axial-tapered and Rayleigh-stepped ring seals; and radial-tapered, radial-stepped, and spiral-groove face seals. Hydrostatic ring, segmented, and face seals were judged the most promising designs.

A study is also being conducted to evaluate hydrodynamic seals for the liquid oxygen turbopump. ${ }^{32}$ Hydrodynamic seals generate a hydrodynamic lifting force during shaft rotation that allows the seal to follow shaft perturbations. This enables the seal designer to use tighter clearances and hence reduce leakage.

Two types of hydrodynamic seals are being investigated: a spiralgrooved, liquid oxygen primary face seal and a Rayleigh-stepped, heliumpurged ring seal. The objectives are to validate analytical design tools for these types of seals, to demonstrate their performance and life at surface velocities up to 600 $\mathrm{ft} / \mathrm{sec}$ while sealing 750-psia liquid oxygen and 200-psia helium, and to determine their sensitivity to manufacturing tolerances.

\section{FACE SEAL FOR TWO-PHASE FLOW}

In recent years there has been a strong interest in the development of face seals ${ }^{2-9,33-37}$ and face seals for two-phase flow. As stated previously, two-phase flow is a common condition in turbomachine operation. Seal dynamics in twophase flows is based on the single- phase (1iquid or vapor) dynamics plus the phase change.

For a face seal with single-phase flow the clearances are less than 0.0001 in and small irregularities have significant effects. These effects are shown in Figure 5(a). In the vapor phase the fluid molecule's mean free path can be of the same order of magnitude as the clearance; slip flow theory needs to be applied.

The dynamics are determined by the opening and closing forces on the face seal. The seal opening forces are related to the pressure profile; the closing forces are related to the geometry, the spring loads and the friction force (Figure $5(b))$. Balanced seals, where the seal opening and closing forces are equal, are noncontacting (hydrodynamic regime); unbalanced seals where the closing force is greater than the opening force are contacting. Contact helps carry the load.

Face seals with diverging clearance exhibit negative stiffness. The critical shaft speed corresponding to the stability threshold is quite high, and the dynamics of runout and assembly are more important. ${ }^{37,38}$ Convergingclearance face seals are generally stable.

Face seals can be pressurized from either the inside or outside diameter depending on the system (e.g., shaft) configuration. Pressurizing at the outside has the advantages of reduced leakage, self-cleaning due to centrifugal forces, and a critical speed where the mass flow rate is zero.

Face seals in two-phase flows have the following important differences related to phase change within the seal: ${ }^{10}$

(1) Leakage decreases.

(2) The pressure profile differs from that of gas or 1iquid with a greater opening force.

(3) There exist two film thicknesses, two angular velocities, and two bulk temperatures supporting the same load.

(4) Seal load is a function of 
the power loss due to fluid shear. (5) The optimum two-phase interface location is located near the seal exit.

(6) Decreased thermal conductivity enhances the stability margin .

(7) Coning improves the stability of a seal but increases the operating film thickness and therefore the leakage rate.

(8) Seals may become unstable when either the fluid temperature or the seal speed is increased.

(9) Choking can occur within the seal during phase change.

Figure 6 shows an example of the pressure profile and loading of face seals in two-phase flow. ${ }^{2}$ The maximum seal load is achieved at a liquid-to-vapor interface (clearance) near the outside radius. The film results in positive stiffness. At higher clearances the seal is stable; at lower clearances the film stiffness is negative and the seal is unstable. According to the loading curve, at a balanced load of $0.37 \mathrm{kN}$ the seal would open in gas and collapse in liquid; at a balanced load of $0.45 \mathrm{kN}$ the seal would collapse in either all gas or all liquid but be stabilized in a two-phase condition.

Several computer codes have been developed to study the steadystate and dynamic performance of annular and face seals with twophase flow for both laminar and turbulent conditions. ${ }^{16}$ These codes were used extensively to deduce the design information discussed previously.

\section{SWIRL BRAKES}

Early versions of the Space Shuttle Main Engine (SSME) High Pressure Fuel Turbopump (HPFTP) interstage seal designs were 33-tooth, three-step labyrinth seals. The whirl forces from leakage past the labyrinth teeth destabilized the rotor when it was operated near and above the rotor first critical speed (22000 rpm). A $175-\mathrm{Hz}$ subsynchronous whirl limited the HPFTP speed to about $25000 \mathrm{rpm}$; with stiff bearing mounts and smooth interstage seals the HPFTP operated successfully.

The initial vibration problems with the HPFTP involved synchronous and subsynchronous vibration motion associated with the first critical speed. The problem was initially improved by replacing the original stepped labyrinth tooth on a rotor turbine interstage seal with a smooth-rotor/ honeycomb-stator seal. The problem was finally resolved by adding a swirl brake.

The use of swirl brakes (shown in Fig. 7) to stabilize rotors is a standard feature in many machines with interstage labyrinth seals (e.g., turbine interstage seals, shown in Fig. 8) to enhance stability. The effectiveness of swirl brakes has been demonstrated in a NASA-sponsored study on rotordynamic stability. ${ }^{11}$

The swirl brake is most effective when the pressure drops are high, at high surface speeds, or both. They are most effective for short seals (length-to-diameter ratio $L / D<1)$, ineffective with high L/D honeycomb configurations, weakly effective with high-L/D cylindrical and damper seals, and not needed for brush seals.

Low-L/D seals are attractive for high-performance machines, since the power loss and space (machine mass) are reduced over the high-L/D seal configurations. They are destabilizing for prerotated entry flow. Prerotation swirl in the direction of rotation is destabilizing, but prerotation swirl opposing shaft or disk rotation is stabilizing.

From system stability analyses, ${ }^{39,46}$ the stability margin is related to the average circumferential velocity, which depends on the cross-coupled stiffness, the damping, and the angular velocity. The stability margin is inversely related to the cross-coupled stiffness and directly related to the damping and the angular velocity.

Control of circumferential velocity

average ratio 
ranges from the simple forms with tangential injection to straight-teeth swirl brakes, the more complex higher performance CFD aerodynamic designs, the Alternate Turbopump Design, and preswirlers ${ }^{41}$. Swirl brakes have provided immediate instability relief for many systems.

\section{DYNAMICS}

The earlier experiences with the Space Shuttle Main Engine turbopump, as described in the previous section, prompted the implementation of seal rotordynamic models and experimental verification of dynamic coefficients for seals representative of those used in turbomachines. Results of this study can be useful in the design of rotating machines and have been disseminated to the industry through workshops on Rotordynamic Instability Problems in HighPerformance Turbomachinery held biannually. ${ }^{11}$

This effort has three basic areas: compressible flow seal test facility, analytical and numerical effort, and flow characterization and visualization.

COMPRESSIBLE FLOW SEAL TEST FACILITY - The facility, shown in Figure 9, can test seal configurations to $20000 \mathrm{rpm}$ and 250 psi with air. The facility is unique in terms of rotor speed, supply pressure, and parameters identification.

Inlet preswirl is a control parameter, as is surface roughness. Force, frequency, pressure, temperature, and displacements are the primary measurements and provide inputs to a computational code for determining dynamic coefficients, such as direct stiffness and damping and cross-coupled stiffness and damping. Data for cylindrical, tapered, labyrinth, spiral-groove, four-stage-brush, rub-tolerant, damper, step, and honeycomb seals have been obtained and reported. ${ }^{11}$ Figure 10 shows some of the seals tested in this facility.

Analytical and numerical develoopment - The analytical code uses a two-dimensional, time-dependent, constant-property, bulk flow model based on Hir's, Moody's, or Colebrook's relations for wall shear stress with inlet losses introduced through "static tests." Although bulk flow models are limited and inlet losses and secondary flows are critical to the analysis, the bulk model predictions agree reasonably well with experimental results for simple geometries and provide trends that can be assessed experimentally or numerically.

At elevated pressures and surface speeds the bulk flow models have inherent deficiencies. Recent work indicates that inlet effects, eccentricity, wall shear, and secondary flows have significant contributions to the overall dynamics. The compressible flow analyses are advanced, incorporating surface roughness and eccentric rotor placement and allowing circumferential fully choked or fully unchoked conditions.11,42 However, they are limited and can only account for entrance, surface, and secondary flows in a heuristic way. The asymmetry of choking may be beyond the current theoretical capability and may yield to experimental or numerical solutions. Flow characterization and visualization - Flow visualization provides important qualitative and quantitative information for modeling and physical understanding. A system was developed to provide quantitative, qualitative, and bulk flow results. ${ }^{43}$ In this system, laser light and flow tracers are used to characterize the flow field. Particle position, velocities, and acceleration are determined to provide a quantitative description of the flow field.

Visualization and pressure drop data for flows through 1 inear brush seals have been assessed. Flow patterns have been described and models have been postulated on the basis of leakage that is either normal or aligned with the flow as well as on the basis of porosity and flow resistance. 20 
A three-dimensional laser doppler anemometer (LDA) system has also been developed to provide detailed maps of the flow field and fundamental turbulence relations, such as Reynolds stresses in annular seal configurations. This system has produced some of the first Reynolds stress data for simulated labyrinth and smooth seals.

Data sets include annular, annular eccentric (0.5), and labyrinth seals with no rotor whirl and annular and labyrinth seals with a whirl ratio of 1 and an eccentricity of 0.5 for selected Taylor and Reynolds numbers. Figure 11 shows the three-dimensional LDA flow modeling results for an annular seal. The normalized axial velocity contours are for data taken inside a whirling annular seal. The flow is highly three dimensional with large radial velocity gradients and recirculation zones on the rotor surface near the inlet. The maximum axial velocity migrates from the "pressure" side of the rotor at the inlet to the "suction" side at the exit. Turbulence production is very large near the inlet but equilibrates with dissipation fairly quickly. These results are in qualitative agreement with observations made by others. ${ }^{\mathbf{4 4 - 4 8}}$

The key results of the seal dynamics study are:

1. Preliminary results for an $\mathrm{L} / \mathrm{D}=1 / 6$ labyrinth seal ${ }^{\mathbf{4 9}}$ show that at low pressures and low rotational speeds theoretical predictions appear to be adequate. However, agreement became progressively worse as pressure and speed increased.

2. Two honeycomb seals at $L / D=$ $1 / 3$ have been tested at three clearances. Preliminary results show large cross-coupled stiffness coefficients and large values of damping but insensitivity to swirl.

3. Flow interactions with honeycomb cells were complex. Flat-plate friction factor data for various honeycomb cell configurations at several clearances over a range in Reynolds number have been reported. ${ }^{50,61}$ Results from an Air Force program show that the leakage increased by 69 percent when a honeycomb stator land was used with a honeycomb labyrinth seal over that with a smooth land. The honeycomb lands reduce leakage for the conventional straight-through labyrinth seals by 24 percent.

4. Preliminary tests with a 30-degree helically grooved-stator/ smooth-rotor seal developed very large forces. The test results were interesting in that large negative tangential forces were developed. They suggested that helically grooved seals could be designed to enhance rotordynamic stability rather than merely to minimize their destabilizing influence.

\section{VERIFIED KNOWLEDGE-BASED SEALS CODES}

A seven-year effort was established in 1990 to develop a verified knowledge-based system for seals. The program will develop two types of KBS seals codes: industrial and scientific. ${ }^{9}$ The industrial codes are less complex twodimensional codes for seal design; the scientific codes are full threedimensional CFD codes for intensive analysis of complex designs.

The numerical computation and verification of seal flows include parametric sensitivity, design and CFD concepts with attendant knowledge bases that quantize time-dependent electromechanical, thermomechanical, or fluid mechanical interactions (e.g., electromagnetic, electrostatic, thermal, fluid, rotor, and stator) for aerospace propulsion system turbomachine components. The knowledge base will contain a wide variety of seal configurations and associated analysis modules as well as the data base utilized for code development and verification.

To ensure accuracy of the codes and usefulness of the end products, the codes are discussed at and distributed to the U.S. industry through annual workshops. The progress of this program is being monitored by the NASA project team with the assistance of a peer review group. The peer review group 
consists of seals and rotordynamic experts from the industry, academia and government agencies.

Currently, the scientific CFD code is being extended to three dimensions; industrial codes for three types of cylindrical seals are being tested. Some of the CFD code results have been reported, including results with rim seals and "lid-driven cavities." CFD comparisons with experimental data are being completed.

\section{SUMMARY}

Turbomachine seal leakage and dynamics engender parasitic losses that degrade engine performance. The objective of current seals activities sponsored by the Earthto-0rbit Propulsion and Space Chemical Engine Technology programs at the NASA Lewis Research Center is to provide the designer and the researcher with the concepts and the data to control seal dynamics and leakage.

Information about studies of brush seals, ceramic rope seals, low-leakage seals for liquid oxygen turbopumps, face seals for two-phase flow, swirl brakes, dynamics, flow modeling, and seals code development has been presented. The seal dynamics study and code development effort include a variety of seal configurations, such as bore (cylindrical), labyrinth, face, tip, honeycomb, spiral groove, felt metal, brush, rim, and driven-cavity seals, along with swirl brakes, damper seals, and high-compliance woven seals.

The results of these studies have been highly beneficial to the aerospace community. Results are disseminated through Workshops on Rotordynamic Instability Problems in High-Performance Turbomachinery and Workshops on Seals Flow Code Development. The workshops and the conference proceedings from the workshops have proven a successful instrument for disseminating information and a forum where researchers and designers can maintain credibility at the leading edge of the technology.

\section{REFERENCES}

1. Hendricks, R.C., Carlile, J.A, and Liang, A.D., "Some Sealing Concepts - A Review, PART A Industrial, Proposed and Dynamic, PART B Brush Seal Systems", ISROMAC-4 The Fourth International Symposium of Transport Phenomena and Dynamics of Rotating Machinery, Honolulu, Hawaii, USA, April 5-8, 1992 .

2. Ludwig, L.P., and Greiner, H.F., "Designing Mechanical Face Seals for Improved Performance", Part 1. B and Part 2. Lubrication, Mechanical Engineering Dec. 1978, pp 18-23.

3. Findley, J.A., Orsino, A.J., and Sneck, H., "Study of Dynamic and Static Seals for Liquid Rocket Engines, Phase II", NASA CR-97575, May 1968.

4. Findley, J.A., Sneck, H. , and Reilly, J.A., "Seals Design Guide: Study of Dynamic and Static Seals for Liquid Rocket Engines", NASA CR-109646, Jan 1970.

5. Leefe, S.E., "Face Seals for Liquid Rocket Engine Turbopumps", BHRA Report No. CR 3058, June 1989.

6. BHRA, Proceedings of the (1st (1961) to 13th (1992)) International Conference on Fluid Sealing.

7. Buchter, H.H., "Industrial Sealing Technology", John Wiley and Sons, New York, 1979.

8. NASA, "Liquid Rocket Engine Turbopump Rotating-Shaft Seals", NASA SP-8121, Feb. 1978.

9. NASA, "Seals Flow Code Development", NASA CP 10070, 1991.

10. Hughes, W.F., Basu, P., Beatty, P.A., Beeler, R.M., and Lau, S., "Dynamics of Face and Annular Seals with Two-Phase Flow", NASA CR-4256, 1989 .

11. Childs, D. W., Vance, J. M., and Hendricks, R. C.: Eds.."Rotordynamic Instability Problems in High Performance Turbomachinery",

11a 1980 Proceedings, NASA CP-2133

11b 1982 Proceedings, NASA CP-2250

11c 1984 Proceedings, NASA CP-2338 
11d 1986 Proceedings, NASA CP-2409

11 e 1988 Proceedings, NASA CP-2443: Nikolajsen et al

$11 \mathrm{f} 1990$ Proceedings, NASA CP-3122

12. Fleming, D.P., "Effect of Seals on Rotor Systems", The Shock and Vibration Bulletin, No. 52, Naval Res. Center, Washington DC, May 1982 .

13. Fleming, D.P., "High Stiffness Seals for Rotor Critical Speed Control", ASME Paper, 77-DET-10, 1977.

14. Ferguson, J.G., "Brushes as High Performance Gas Turbine Seals", Gas Turbine and Aero Engine Congress, Amsterdam, The Netherlands, ASME Paper 88-GT-182.

15. Flower, R., "Brush Seal Development Systems", AIAA 90-2143 AIAA/SAE/ASME/ASEE 26th Joint Propulsion Conference, July 16-18, 1990, Orlando, FL.

16. Chupp, R., and Nelson P., "Evaluation of Brush Seals for Limited Life Gas Turbine Engines", AIAA 90-2140, AIAA/SAE/ASME/ASEE 26th Joint Propulsion Conference, July 16-18, 1990, Orlando, FL.

17. Chupp, R. and Dowler, C., "Flow Coefficients for Brush Seals", 27th Joint Propulsion Conf., Sacramento CA, AIAA Paper 91-3390, June 24-27, 1991 .

18. Holle, G., and Krishnan, M., "Gas Turbine Engine Brush Sea1 Applications", AIAA 90-2142, AIAA/SAE, 1990, Orlando, FL.

19. Conner, K.J., and Childs, D.W., "Brush Seal Rotordynamic Damping Characteristics", AIAA 90-2139, AIAA/SAE/ASME/ASEE 26th Joint Propulsion Conference, July 16-18, 1990, Orlando, FL.

20. Hendricks, R.C., Schlumberger, J., Braun, M.J., Choy, F., and Mullen, R., "A Bulk Flow Model of a Brush Seal System", ASME Paper 91-GT-325, 1991.

21. Carlile, J.A., Hendricks, R.C., Yoder, D.A., "Brush Seal Leakage Performance with Gaseous Working Fluids at Static and Low Rotor Speed Conditions", to be presented at The 1992 IGTI Conference in Cologne, Germany.

22. Hendricks, R.C., Carlile, J.A., Yoder,D., and Braun, M.J.,
"Investigation of Flows in Bristle and Fiberglas Brush Seal Configurations", ISROMAC-4 The Fourth International Symposium of Transport Phenomena and Dynamics of Rotating Machinery, Honolulu, Hawaii, USA, April 5-8, 1992.

23. Hendricks, R.C., Proctor, M., Schlumberger, J., Braun, M.J. and Mullen, R.L., "Some Preliminary Results of Brush Seal/Rotor Interference Effects on Leakage at Zero and Low RPM Using a Tapered-Plug Rotor", AIAA Paper 91-3390, AIAA/SAE/ASME/ASEE 27th Joint Propulsion Conference, Sacramento, CA, June 24-26, 1991.

24. Schlumberger, J.A.,

Proctor, M.P. and Hendricks, R.C., "Eccentricity Effects on Leakage of a Brush Seal at Low Speeds", NASA TM 105141, 1991 Winter Annual Meeting of ASME

25. Mullerup, J., "Correlated and Predicted Thermodynamic Properties of LNG and Related Mixtures in the Normal and Critical Regions", Advances in Cryogenic Engineering (K.D. Timmerhaus, Ed.) Vol. 20, 1975, pp. 172-194.

26. Simoneau, R. J., and Hendricks, R.C., "Generalized Charts for Computation of Two-Phase Choked Flow of Simple Cryogens. Cryogenics", February 1977, p. 73-76.

27. Hendricks, R. C. and Simoneau, R. J., "Two-Phase Choked Flow in Tubes with Very Large L/D", paper BC-1, CEC/ICMC Conference, Boulder, Colorado, August 2-5, 1977. 28. Hendricks, R. C. and Sengers, J. V., "Application of the Principle of Similarity to Fluid Mechanics--Water and Steam: Their Properties and Current Industrial Applications", 9th International Conference on Properties of Steam, J. Straub and K. Scheffler, eds., Pergamon Press, Oxford, 1980. 29. Hendricks, R. C., Braun, M. J., Mullen, R. L., and Burcham, R. E., "Performance Turbomachines as for Space Shuttle Main Engines", Workshop on Heat and Mass Transfer in Rotating Systems, Symposium on Transport Phenomena in Rotating Machinery, Honolulu, Hawaii, April 
28-May 3, 1985.

30. Steinetz, B.M., Mutharasan, R., Du, G., and Ko, F., "Braided Rope Seals for Hypersonic Engine Applications: Design Concept and Leakage Flow Modelling", ISROMAC-4 The Fourth International Symposium of Transport Phenomena and Dynamics of Rotating Machinery, Honolulu, Hawaii, USA, April 5-8, 1992.

31. Shapiro, W. and Lee, C.C., "Advanced Helium Purge Seals for Liquid Oxygen (LOx) Turbopumps", NASA CR 182105, March 1989.

32. Shapiro, W. and Hamm, R., "Seal Technology for Liquid Oxygen (LOx) Turbopumps", NASA CR-174866, November, 1985.

33. Sneck, H.J., "The Effects of Geometry and Inertia on Face Seal Performance-Laminar Flow", Trans. ASME Jourl. of Lubrication Technology, April 1968, pp 333-341.

34. Metcalf, R., "Predicted Effects of Sealing Gap Convergence on Performance of Plain End Face Seals", ASLE Transactions, Vol. 25, 1982, 3, pp.361-371.

35. Lebeck, A.0., "Contacting Mechanical Seal Design: Simplified Hydrostatic Model", Proc. of the Eleventh International Conference on Fluid Sealing, BHRA, 1987, Paper No. F1, July 1980, pp 341-349.

36. Shapiro, W. and Colsher, R., "Steady-state and Dynamic Analysis of a Jet Engine, Gas Lubricated Shaft Seal", ASLE Transactions, Vol.17, 1974, 3, pp. 190-200.

37. Etsion, I., " Dynamic Response to Rotating Seat Runout in Noncontacting Face Seals", Trans. ASME Jourl of Lubrication Technology, Vol. 102, October 1981, pp. 587-592.

38. Etsion, I., and Burton, R.A., "Observation of Self-Excited Wobble in Face Seals, Trans.", ASME Jour. of Lubrication Technology, Vol 101 , October 1979, pp 526-528.

39. Muszynska, A., and Bently, D.E., "Frequency-Swept Rotating Input Perturbation Techniques and Identification of the Fluid Force Models in Rotor/Bearing/Seal Systems and Fluid Handling Machines", Journal of Sound and Vibration
(1990) $143(1)$, pp 103-124.

40. von Pragenau,

G.L.,

"Damping Seals for Turbomachinery", NASA TP 1987, March 1982.

41. Miller, E.H., "Rotor

Stabilizing Labyrinth Seal for Steam Turbines", Unites States Patent No. 4,420,161, December 1983 .

42. Nelson, C., "Rotordynamic Coefficients for Compressible Flow in Tapered Annular Seals", ASME Trans. Jourl of Engineering for Gas Turbines and Power, Vol. 107, pp. 318-325.

43. Braun, M.J., Ida, N., Batur, C., Rose, B., Hendricks, R.C., Mullen, R.L., "A Non-Invasive Laser Based Method in Flow Visualization and Evaluation in Bearings", Paper C 347/143, International Conference on Tribology Friction, Lubrication and Wear, pp. 37-45, The Institution of Mechanical Engineers July 1-3, 1987 , London, Great Britain.

44. Braun, M.J. and Hendricks,

R.C., "Experimental Investigation of Vaporous/Gaseous Cavity Characteristics of an Eccentric Shaft Seal (or Bearing)", presented at the ASLE/ASME Joint Lubrication Conf., Washington, D.C., October 57, 1982 .

45. Hendricks, R.C., "Investigation of a Straight Cylindrical Seal for High Performance Turbomachines", NASA TP1848,1981 .

46. Hendricks, R.C., "Investigation of a Three Step Cylindrical Seal for High Performance Turbomachines", NASA TP1849,1981 .

47. Hendricks, R.C.,

"Investigation of a Three Step Labyrinth Seal for High Performance Turbomachines", NASA TP-1850, 1981. 48. Tam, L.T., Przekwas, A.J. , Muszynska, A., Hendricks, R.C., Braun, M.J. and Mullen, R.L., "Numerical and Analytical Study of Fluid Dynamic Forces in Seals and Bearings", J. of Vibration, Acoustics, Stress, and Reliability in Design, ASME, $110,1988, p$ 315325 (Won H.H. Jeffcott Award). 49. Pelleti, J. and Childs, D., "A Comparison of Theoretical 
Predictions for the Rotordynamic Coefficients of Short (L/D=1/6) Labyrinth Seals", Rotating Machinery and Vehicle Dynamic, DE-Vol 35, ASME, Proceedings of the 13th Vibration Conference, 1991. 50. Ha, T.W., Morrison, G.L., and Childs, D., "Friction-Factor Characteristics for Narrow Channels with Honeycomb Surfaces", ASME Journal of Tribology, to be published, 1991, (ASME 91-Tri-21).

51. Ha, T.W. and Childs, D., "Friction-Factor Data for Flat-Platé Tests of Smooth and Honeycomb Surfaces", ASME Journal of Tribology, to be published, 1991, (ASME 91-Tri-20).

52. Stocker, H.L, Cox, D.M. , and Holle, G.F., "Aerodynamic Performance of Conventional and Advanced Design Labyrinth Seals with Solid-Smooth, Abradable, and Honeycomb Lands", NASA CR-135307, Nov. 1977.

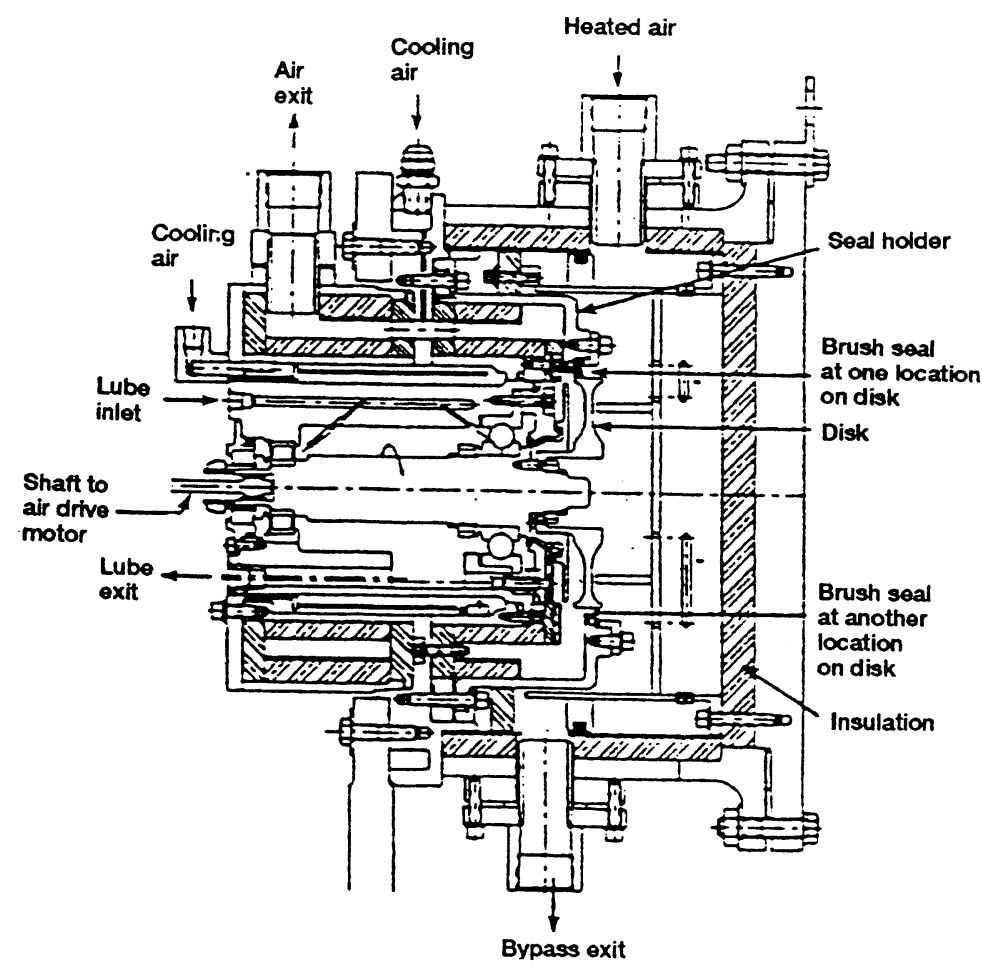

Figure 2 - Cross section of hot-gas brush seal rig

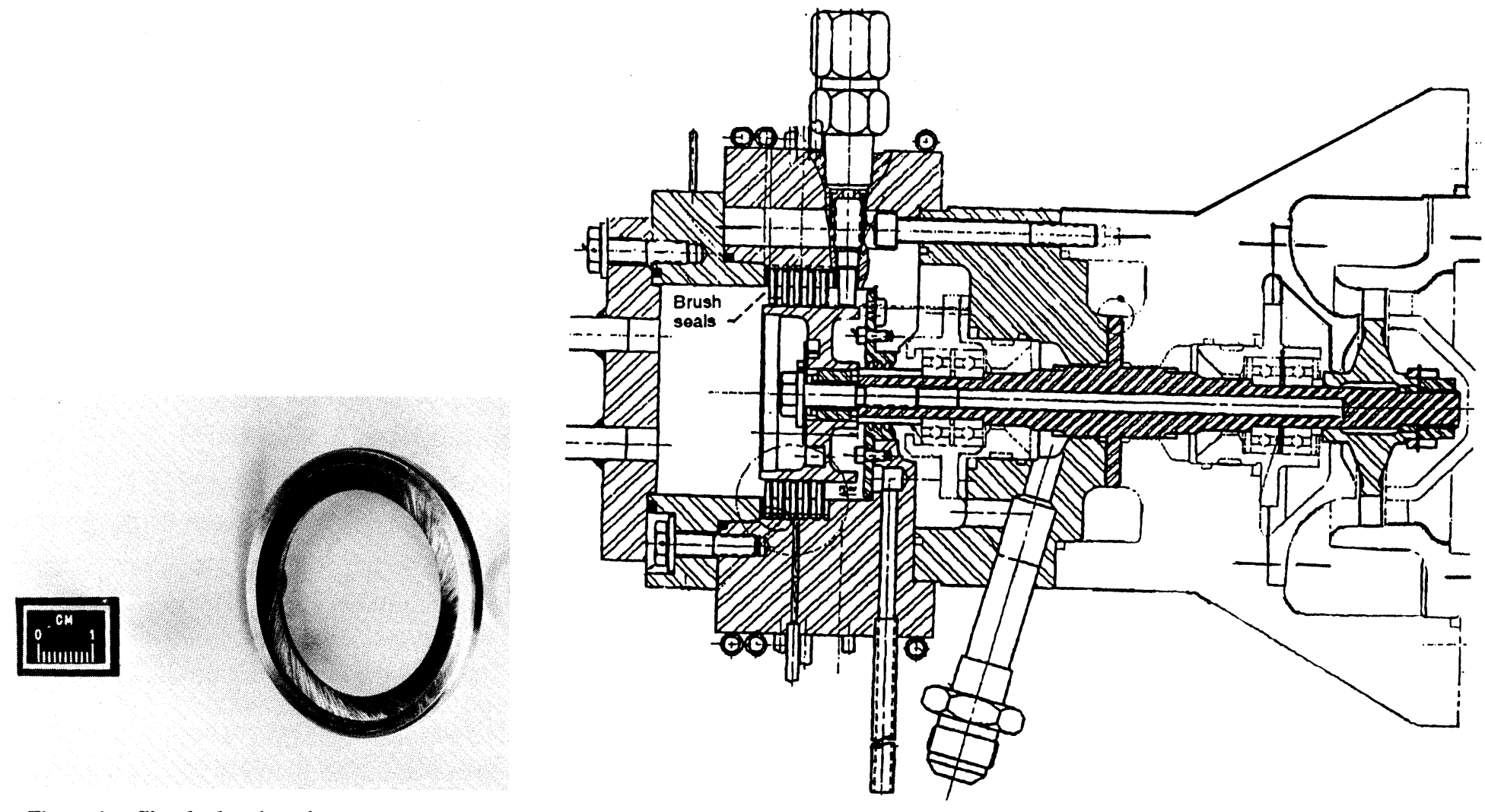

Figure 1. - Circular brush seal.

Figure 3 - Cryogenic test rig 

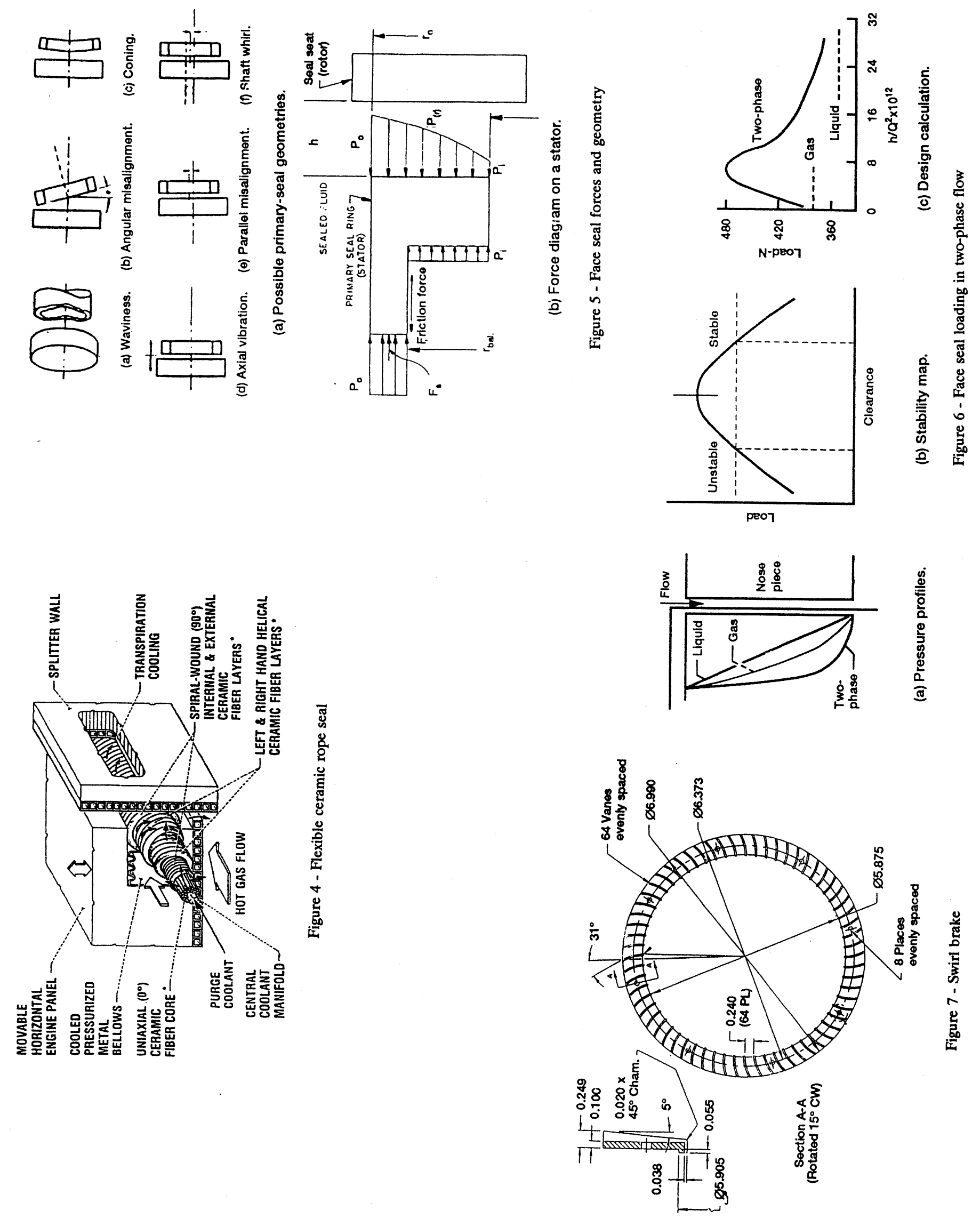


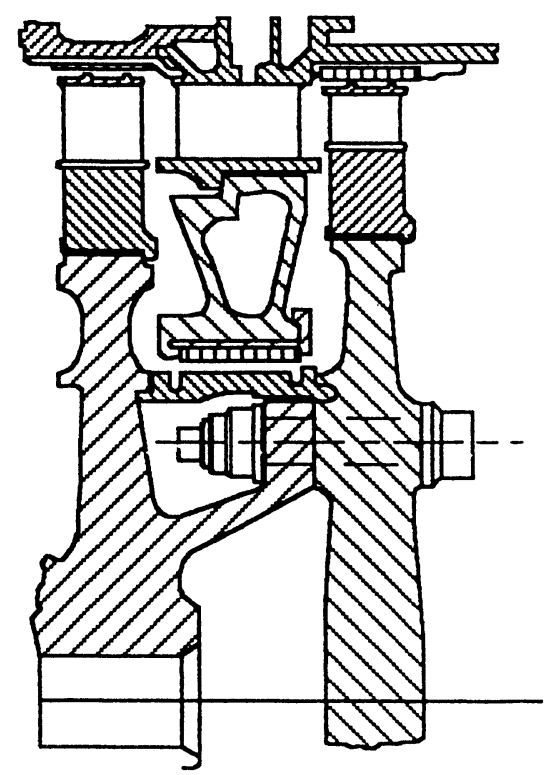

Figure 8 - High-pressure oxgyen turbopump turbine interstage seal

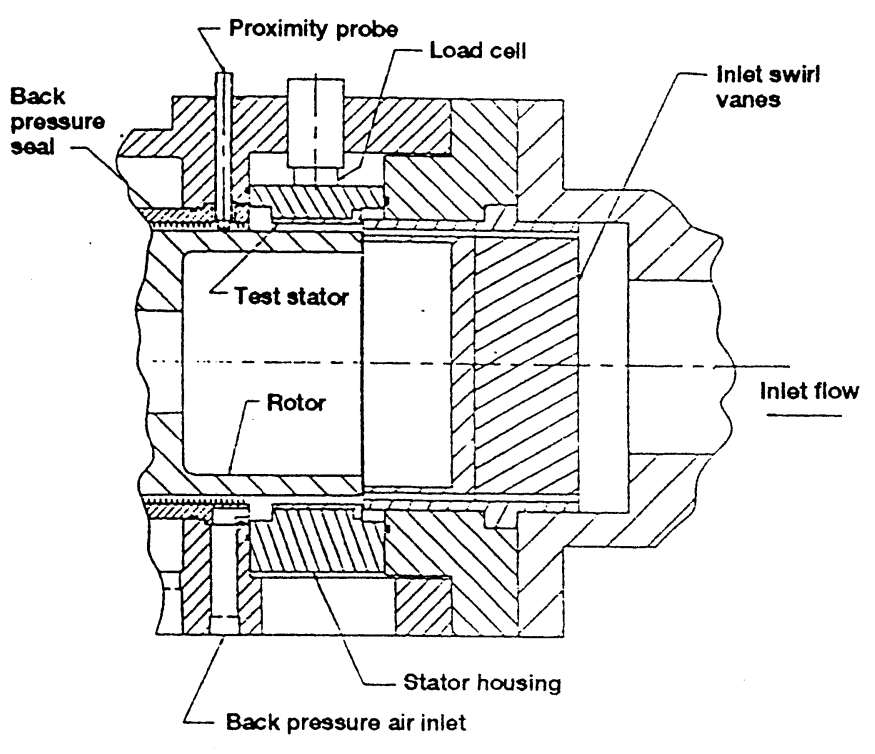

Figure 9 - Texas A\&M seal test rig

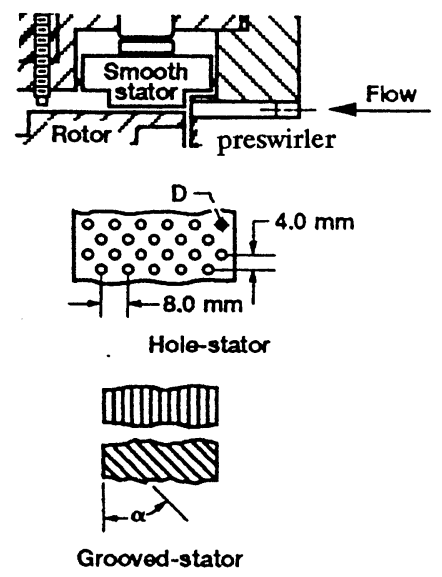

Grooved-stator

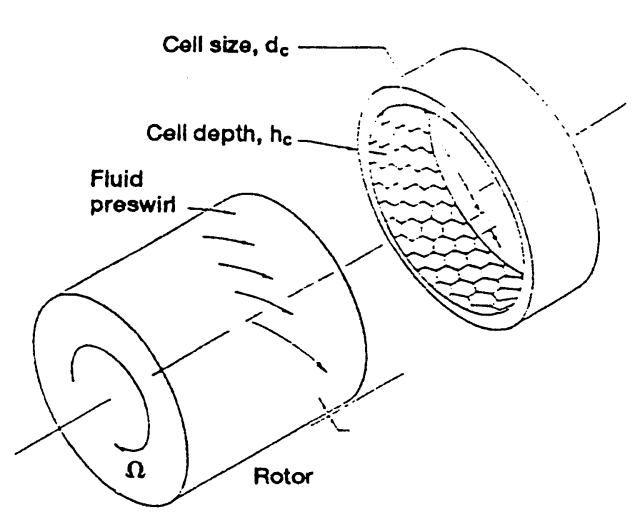

Figure 10 - Texas A\&M seals tested
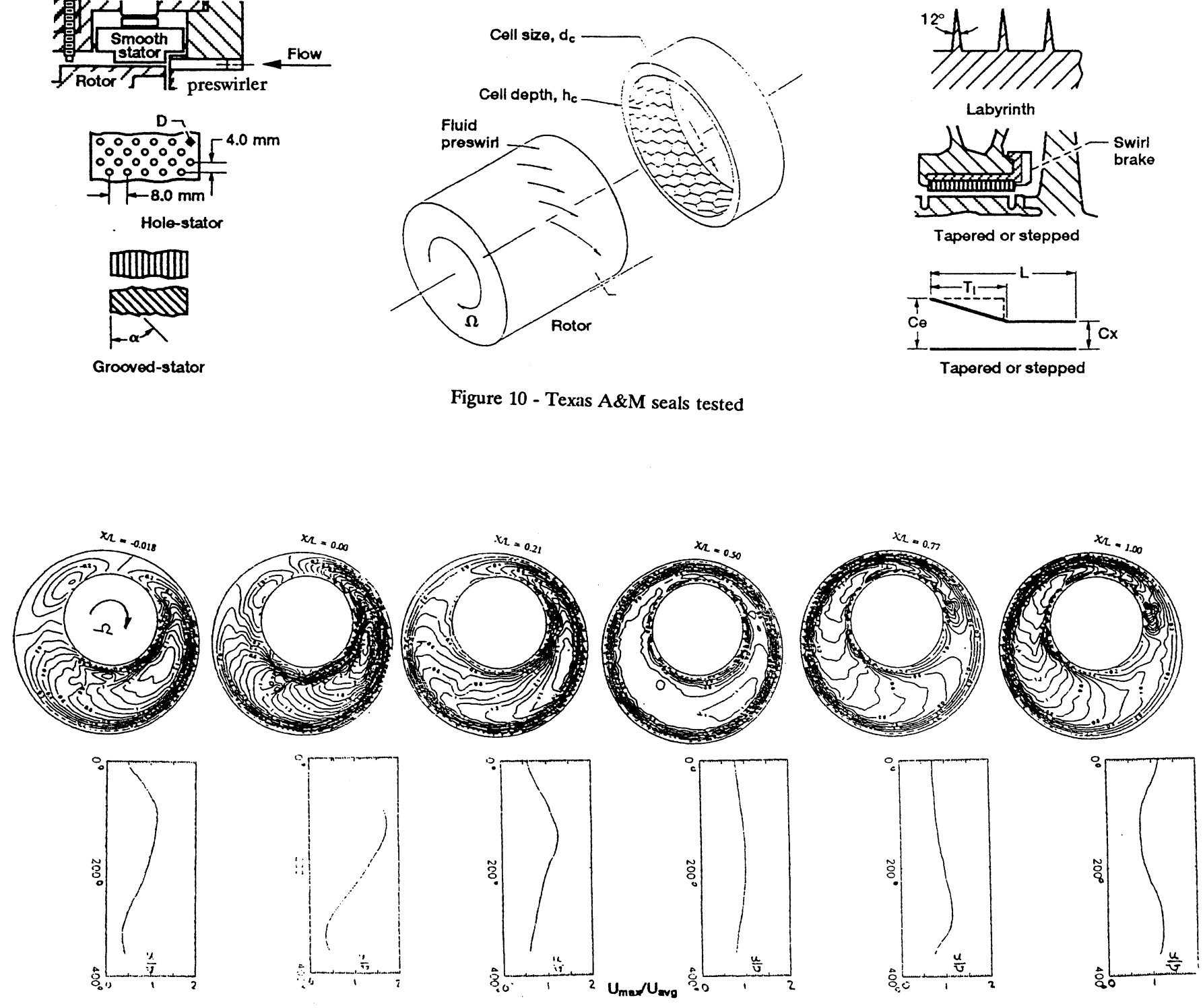

Figure 11 - Axial flow variations for an annular seal with whirl ratio $=1.0$ and eccentricity $=0.5$ 


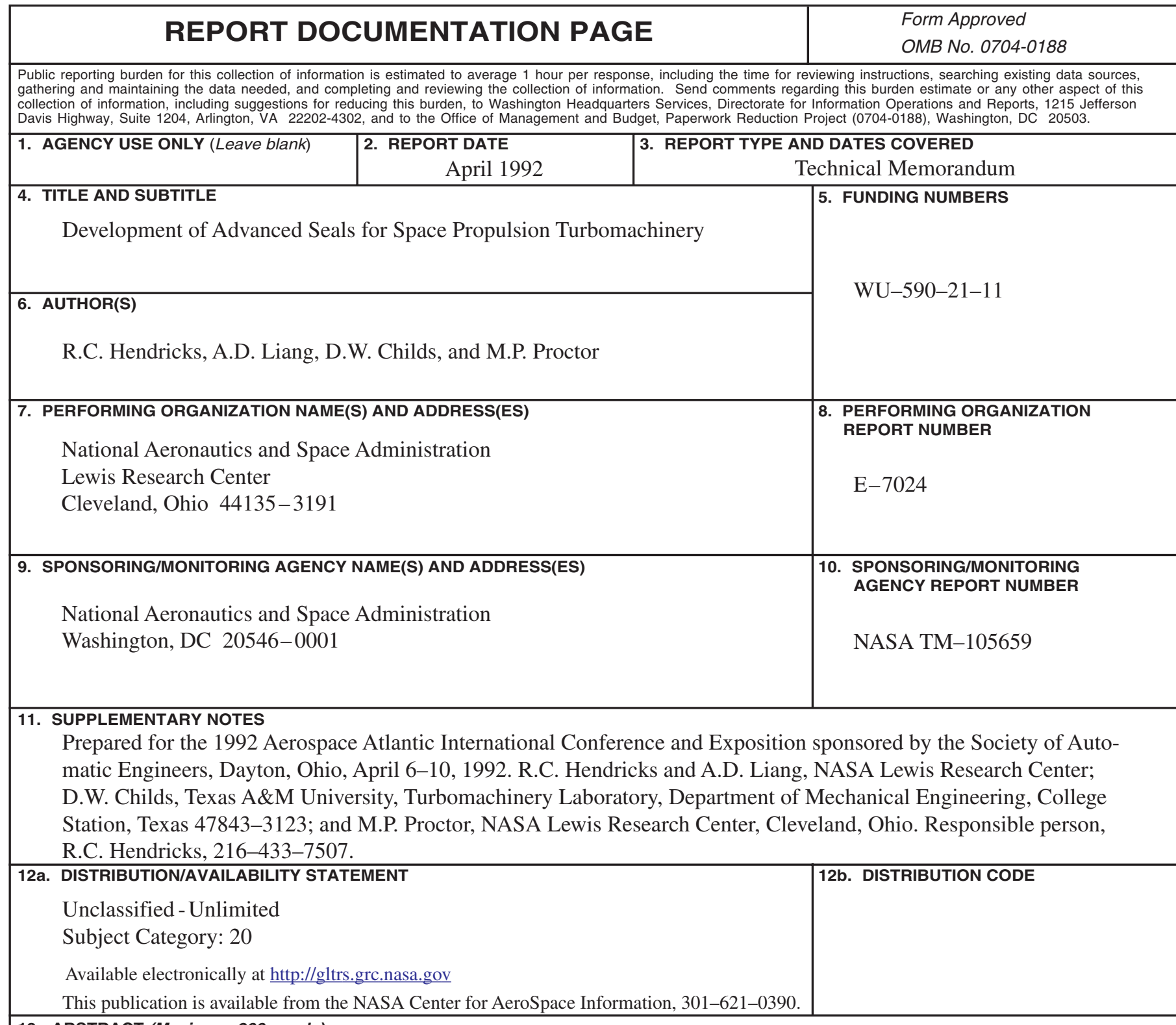

\section{ABSTRACT (Maximum 200 words)}

Current activities in seals for space propulsion turbomachinery that the NASA Lewis Research Center sponsors are surveyed. The overall objective is to provide the designer and the researcher with the concepts and the data to control seal dynamics and leakage. Included in the program are low-leakage seals, such as the brush seal, the "ceramic rope" seal, low-leakage seals for liquid oxygen turbopumps, face seals for two-phase flow, and swirl brakes for stability. Two major efforts are summarized: a study of seal dynamics in rotating machinery and an effort in seal code development.

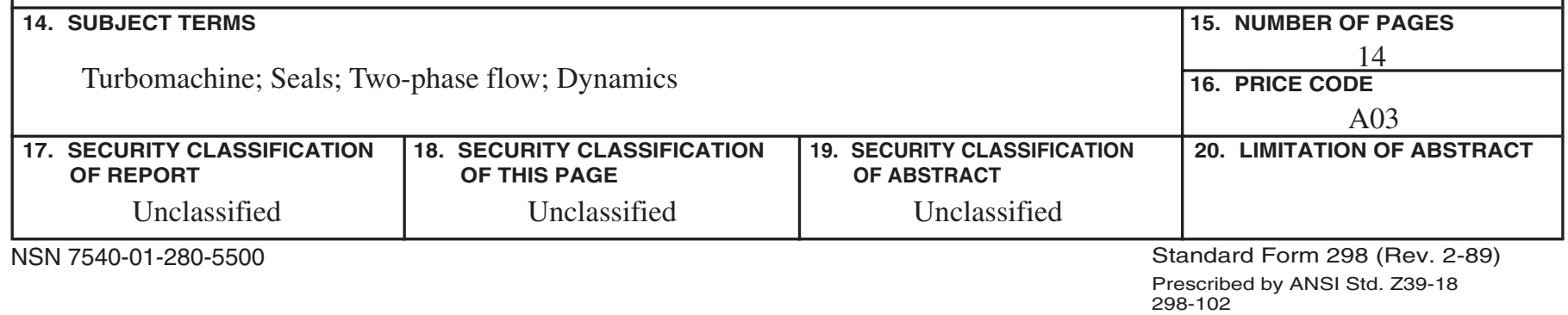

